Research Article

\title{
Preparation of Nickel Nanocatalysts and Application to the Hydrodechlorination of 3-Chlorophenol under Liquid Phase
}

\author{
Thanh Thien Co $\mathbb{D}^{1},{ }^{1,2}$ Thi Kim Anh Tran, ${ }^{1}$ Thi Huong Ly Doan, ${ }^{1}$ and Thi Duyen Diep ${ }^{1}$ \\ ${ }^{1}$ University of Science, Ho Chi Minh City, Vietnam \\ ${ }^{2}$ Vietnam National University, Ho Chi Minh City, Vietnam \\ Correspondence should be addressed to Thanh Thien Co; ctthien@hcmus.edu.vn
}

Received 23 August 2020; Revised 20 February 2021; Accepted 25 February 2021; Published 4 March 2021

Academic Editor: Suresh Kannan Balasingam

Copyright (C) 2021 Thanh Thien Co et al. This is an open access article distributed under the Creative Commons Attribution License, which permits unrestricted use, distribution, and reproduction in any medium, provided the original work is properly cited.

\begin{abstract}
Nickel nanoparticles were successfully synthesized via the reduction of nickel salt using ethylene glycol (EG) and sodium borohydride $\left(\mathrm{NaBH}_{4}\right)$ as reducing agents. These nickel nanoparticles were then loaded on the supports as Ni-X $(\mathrm{X}=\mathrm{vanadium}$ phosphorus oxides (VPO), $\mathrm{TiO}_{2}$, and $\mathrm{ZnO}$ ) in high loading yield. The optical properties of these catalysts were characterized by $\mathrm{UV}$-vis spectroscopy, the structure of Ni-X was studied by powder X-ray diffraction (PXRD), the distribution of Ni particles in X was studied by transmission electron microscopy (TEM), and the specific surface area of Ni-X was evaluated by $\mathrm{N}_{2}$ adsorption isotherm analysis at $77 \mathrm{~K}$. All results corroborated the loading process. Indeed, TEM image indicated that the nickel nanoparticles size is in the range of $14 \div 16 \mathrm{~nm}$ and fully loaded into X. The activities of these catalysts were performed on the hydrodechlorination of 3-chlorophenol in the presence of sodium hydroxide as base at atmospheric pressure and at RT. The results showed that $\mathrm{Ni}-\mathrm{X}$ exhibited high activities up to $98 \%$ within $90 \mathrm{~min}$ in the case of $\mathrm{Ni}-\mathrm{ZnO}$ catalyst.
\end{abstract}

\section{Introduction}

Every year, hundreds of chemical plants in the world produce tens of millions of tons of chlorine derivatives and large amounts of sodium hydroxide to serve for the industrial production according to the World Chlorine Council [1]. Among these, more than $21 \%$ of the chlorine was used to produce chlorinated organic compounds. These compounds were widely used as raw materials [2-4], solvents for chemical processes [5-7], textile, dry cleaning, and pesticide production. Due to the lack of high technology and management, these used substances were discharged directly into the environment causing serious pollution, especially for human health [8]. Therefore, numbers of researchers all over the world suggested to find the solution for this problem. The oxidative degradation, biological decomposition, and hydrodechlorination were considered as alternative methods of removing large amounts of organic pollutants in which the hydrodechlorination method promises high efficiency and safety and gives a beneficial product in industry.
One of the useful methods to hydrodechlorinate chlorine derivatives is using nanomaterials because of the low cost and easy to control the process. In reality, Xia et al. reported the hydrodechlorination of monochlorophenol with palladium nanoparticles supported on activated carbon as catalyst, and the conversion of chlorine substrates reached over 99\% within 50 min reaction [9]. Likewise, Wiltschka and coworkers loaded palladium nanoparticles on film nanocomposite membranes with low concentration to completely recover benzene [10]. Peng prepared silver-palladium alloy to dechlorinate 2,4-dichlorophenol in high efficiency, and it is over $90 \%$ conversion within $240 \mathrm{~min}$ [11]. Nevertheless, the catalyst seemed to be poisoned in long-term reaction [12]. Besides, Zang et al. isolated most of the benzene from the dechlorinated process under $\mathrm{Pd}(\mathrm{Phen}) \mathrm{Cl}_{2}$ as a homogeneous catalyst precursor [13]. However, palladium nanomaterials are well-known noble metals which perfectly give excellent catalytic activity except that it is more expensive than other common metals. Among them, nickel is one of the bright candidates to replace palladium for 
hydrodechlorination. Unfortunately, not many publications have been found regarding the use of nickel nanoparticles, and most of the process was carried out under gas phase at high temperature. Indeed, $\mathrm{Xu}$ and coworkers presented the nickel nanoparticles which supported low concentration on titanium dioxide as the support and used as a catalyst for the hydrodechlorination of chlorobenzene at $573 \mathrm{~K}$, and the catalyst exhibited excellent stability compared to other catalysts [14].

Herein, we focused on the preparation of nickel nanoparticles and supported on supports such as $\mathrm{TiO}_{2}, \mathrm{ZnO}$, and VPO which are commonly cheap, easy to prepare, and nontoxic materials. All the catalysts were tested for activity through hydrodechlorination of 3-chlorophenol in the presence of sodium hydroxide. All the results will be presented in this report.

\section{Materials and Methods}

2.1. Materials. Reagent-grade nickel chloride hexahydrate 98\% $\left(\mathrm{NiCl}_{2} \cdot 6 \mathrm{H}_{2} \mathrm{O}\right)$, 3-chlorophenol 98\%, titanium dioxide $99 \%$, zinc oxide $99 \%$, ethylene glycol $99.5 \%$ (EG) and sodium borohydride $98 \%\left(\mathrm{NaBH}_{4}\right)$ were purchased from Merck. Sodium hydroxide $98 \%$ and polyvinyl pyrrolidone K-30 (PVP) were purchased from Chinese suppliers. Absolute ethanol and methanol were supplied by Chemsol and used as received. Vanadium phosphorus oxides (VPO) were prepared according to the previous report [15].

2.2. Characterization. The morphologies of nickel catalysts were examined using a scanning electron microscope (SEM, JEOL series JSM-7401F). The X-ray diffraction (XRD) data of all samples were collected in a Bruker D8 powder X-ray with $\mathrm{Cu} K_{\alpha}$ radiation running at $35 \mathrm{kV} / 30 \mathrm{~mA}$ in the $2 \theta$ range of $5^{\circ} \div 75^{\circ}$ with a step size of $0.2^{\circ} / \mathrm{min}$. Nitrogen adsorption-desorption isotherms were collected at $77 \mathrm{~K}$ using Brunauer-Emmett-Teller calculation (BET, AUTOSORB1C Quantachrome, for specific surface area), and all the samples were degassed at $100^{\circ} \mathrm{C}$ and $10^{-6} \mathrm{~Pa}$. GC-MS were obtained by using an Agilent 7890A series model with an electron energy of 20 or $70 \mathrm{eV}$. UV spectra were recorded on Agilent Cary $60 \mathrm{UV}$-Vis. All the catalytic tests were performed in Multireactors Carousel 12 plus.

2.3. Catalyst Preparation. To the $250 \mathrm{cc}$ two-necked round bottom flask, $0.40 \mathrm{~g}$ of PVP and $40 \mathrm{~mL}$ of deionized water (DI) was added. After stirring for $15 \mathrm{~min}, 0.81 \mathrm{~g}$ of $\mathrm{NiCl}_{2} \cdot 6 \mathrm{H}_{2} \mathrm{O}(3.4 \mathrm{mmol})$ was dissolved in the mixture at $80^{\circ} \mathrm{C}$. In another flask, a suitable amount of ethylene glycol and $\mathrm{NaBH}_{4}$ in $50 \mathrm{~mL}$ of DI water was prepared. Then, the solution of reducing agent was added dropwise to the mixture of nickel salt. The mixture was stirred until the black solution was observed.

The nickel nanoparticles were then loaded on the supports (such as $\mathrm{TiO}_{2}, \mathrm{ZnO}$, and VPO, which were calcinated at $120^{\circ} \mathrm{C}$ in $8 \mathrm{~h}$ ) in suitable amount by low pressure method at room temperature. This process was repeated several times to make sure all the nickel nanoparticles were fully loaded into the supports. The obtained powders were dried at $60^{\circ} \mathrm{C}$ under vacuum in $6 \mathrm{~h}$.

2.4. Catalyst Evaluation. In this report, the catalytic activities of nickel nanocatalysts were investigated via the hydrodechlorination of 3-chlorphenol in the presence of alkaline solution. The catalytic evaluation of $\mathrm{Ni}-\mathrm{X}$ was carried out in a $20 \mathrm{~mL}$ multireactor with stirring at room temperature. In this process, $0.1 \mathrm{mmol}$ of $\mathrm{Ni}-\mathrm{X}$ was used in the hydrodechlorination of 3-chlorophenol $(5.0 \mathrm{mmol})$, methanol $(5.0 \mathrm{~mL})$, and $3.0 \mathrm{~mL}$ of $5 \%$ sodium hydroxide solution in water. Hydrogen was directly connected through Schlenk line to the reaction at atmosphere pressure, and the concentration of hydrogen could be considered as constant. The effect of reaction time on process within 30,60, and $90 \mathrm{~min}$ was performed. The conversion of substrate and selectivity of products were analyzed by GC and GC-MS (HP5 column $30 \mathrm{~m} \times 0.25 \mathrm{~mm}$, FID detector). Reproducibility was checked by repeating the measurement several times and was found to be within acceptable limits. Parent supports did not show any catalytic activity.

\section{Results and Discussion}

Nickel nanoparticles were synthesized by the reduction of $\mathrm{NiCl}_{2} \cdot 6 \mathrm{H}_{2} \mathrm{O}$ using EG and $\mathrm{NaBH}_{4}$ as reduction agents. The original blue solution was turned dark when $\mathrm{Ni}^{0}$ nanoparticles formed. The reason EG and $\mathrm{NaBH}_{4}$ were used is that $\mathrm{EG}$ reduction is a common process for the preparation of metal nanoparticles, yet this process needs to be assisted by high temperature or microwave irradiation to improve the reduction performance $[16,17]$. However, sodium borohydride is considered as a force reducing agent which can reduce metallic ions at room temperature, and the disadvantage of sodium borohydride process is the formation of irregular particle size [18]. As a consequence, the combination of ethylene glycol and sodium borohydride process can get better reduction to prepare the nanoparticles.

The obtained dark solution is stable for a long time because nickel nanoparticles were distributed in the PVP solution which is a well-known polymer with a large molecular size and free electron couple on nitrogen site that is able to bond with nickel nanoparticles. Therefore, PVP acts as a protecting agent to avoid the agglutination and deposition of nickel nanoparticles.

As shown in Figure 1, the UV-vis spectrum of nickel nanoparticles indicated that the PVP was unabsorbed on the $\mathrm{UV}$ range, and $\mathrm{Ni}^{2+}$ gave two characteristic peaks at 290 - $390 \mathrm{~nm}$, whereas nickel nanoparticles were absorbed at $270 \mathrm{~nm}$ that could be explained in terms of the results of plasmon resonance occurring on the surface of nickel nanoparticles [19]. It was demonstrated that most of the nickel salt was reduced to $\mathrm{Ni}^{0}$ nanoparticles.

Besides, in order to determine the size of nickel nanoparticles, the catalytic sample was conducted to TEM measurement. Thus, Figures 2(a) and 2(b) showed that nickel nanoparticles are evenly distributed with an average particle size of about $15 \mathrm{~nm}$. On the other hand, 


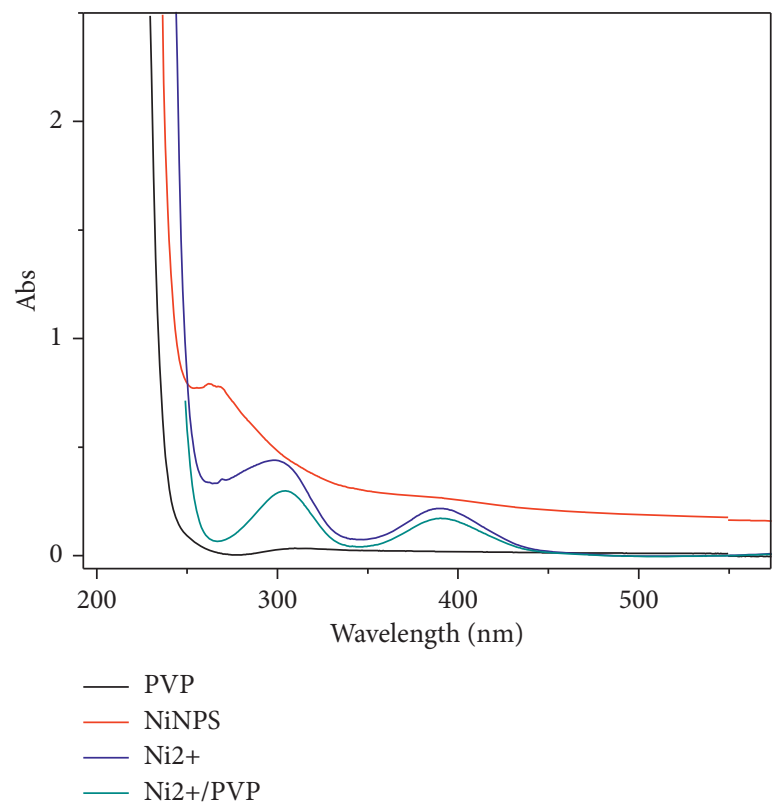

FIGURE 1: UV-vis spectra of nickel nanoparticles solution and reference solutions.

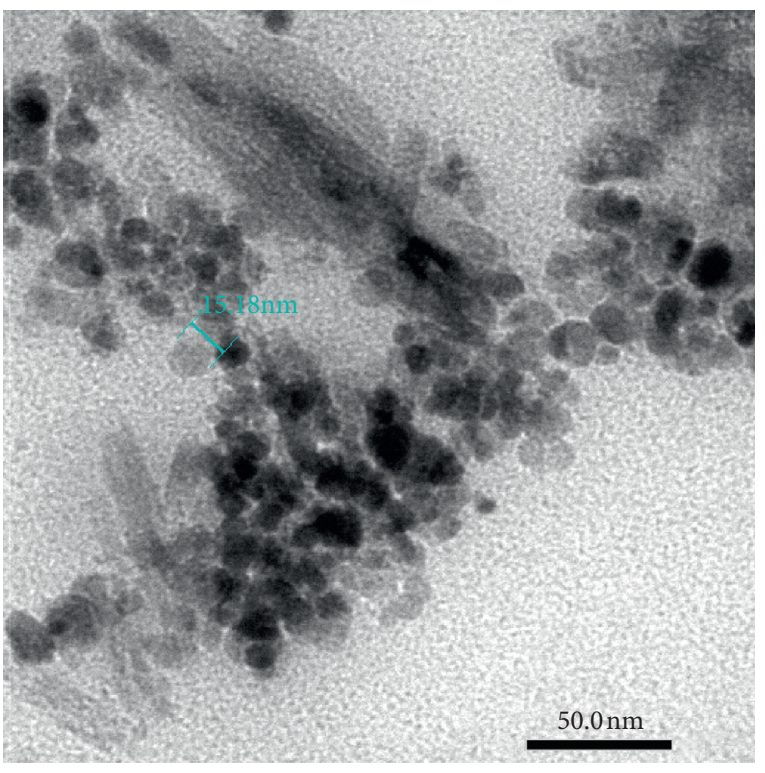

(a)

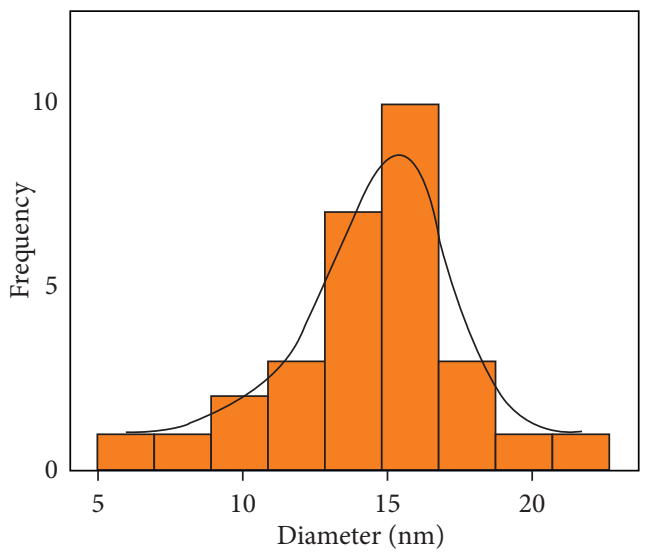

(b)

Figure 2: Continued. 


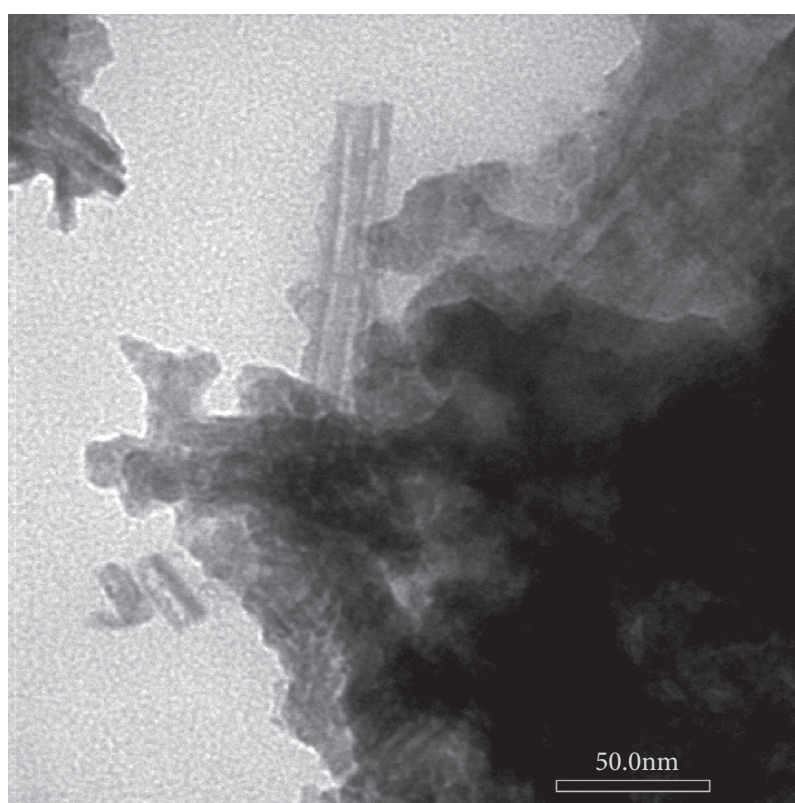

(c)

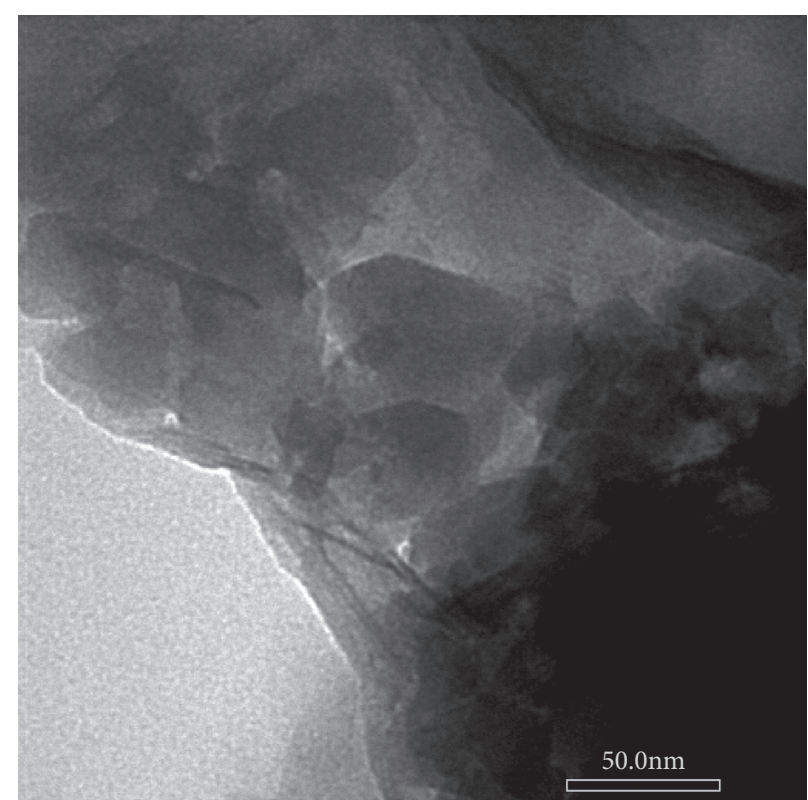

(d)

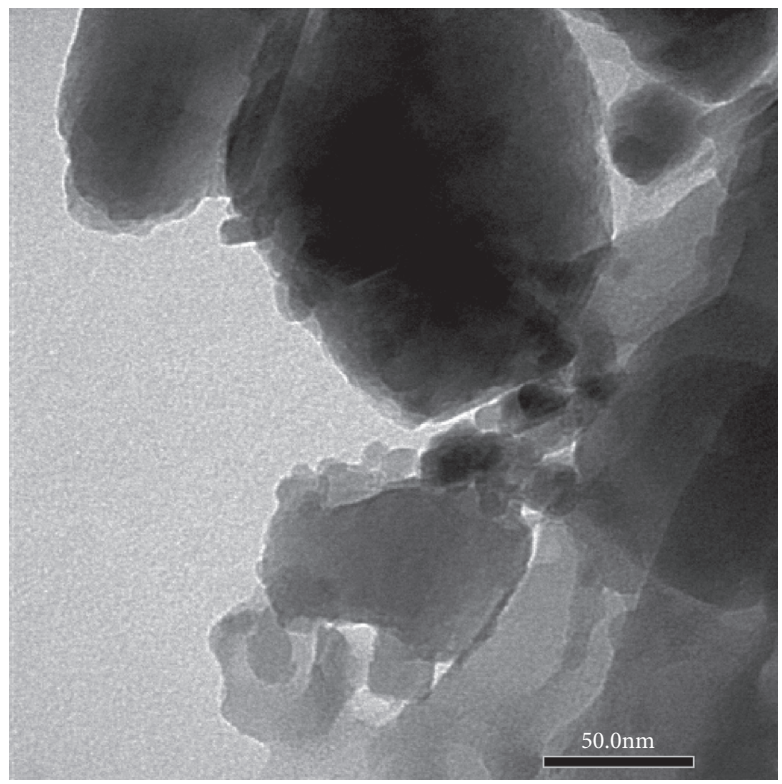

(e)

FIgURE 2: TEM images of (a) Ni nanoparticles; (b) particle diameter; (c) $\mathrm{Ni}^{-} \mathrm{TiO}_{2}$; (d) Ni-ZnO; and (e) Ni-VPO.

Figures 2(c)-2(e) described that most of the nickel nanoparticles were well dispersed on the supports. Furthermore, the morphology surface of catalysts was defined by SEM. In fact, in Figure 3(a), the surface of $\mathrm{Ni}^{-} \mathrm{TiO}_{2}$ was occupied by slit-shaped pores. Meanwhile, the surface of $\mathrm{Ni}-\mathrm{ZnO}$ (Figure 3(b)) was covered by big cylindrical cubic shapes. In contrast, on the surface of Ni-VPO (Figure 3(c)), a number of spherical shapes are formed between the pores that make the surface area of this catalyst bigger than other samples. It is clear that nickel nanoparticles were fully loaded into the supports.

Moreover, Figure 4 illustrated the typical powder XRD patterns of $\mathrm{Ni}-\mathrm{X}$, in which the characteristic peaks of $\mathrm{Ni}^{0}$ appeared at $2 \theta$ of $44.55^{\circ}$ and $51.78^{\circ}$ [19], even though the peaks are rather weak because of the low concentration of $\mathrm{Ni}$ in the samples. Likewise, the corresponding diffraction peaks of parent support $\mathrm{VPO}, \mathrm{TiO}_{2}$, and $\mathrm{ZnO}$ are located at the position of $2 \theta=23.13^{\circ} ; 28.30^{\circ} ; 30.08^{\circ} ; 43.60^{\circ}, 25.40^{\circ}$; $37.90^{\circ} ; 38.75^{\circ} ; 48.15^{\circ} ; 53.95^{\circ} ; 55.13^{\circ}$, and $31.89^{\circ} ; 34.50^{\circ}$; $36.33^{\circ} ; 47.64^{\circ} ; 56.70^{\circ}$; and $62.97^{\circ}$, respectively. This further confirmed that the loading method resulted in a distribution of most of the $\mathrm{Ni}$ particles within the pores of supports, as observed from TEM images. Indeed, the atomic absorption spectroscopy (AAS) indicated that $\mathrm{Ni}$ particles distributed in $\mathrm{VPO}, \mathrm{TiO}_{2}$, and $\mathrm{ZnO}$ were 2.47, 11.71 , and $13.11 \mathrm{wt} \%$, respectively. 


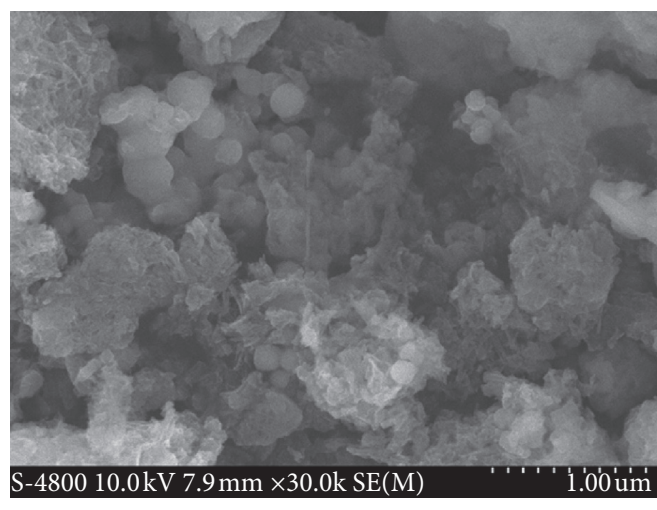

(a)

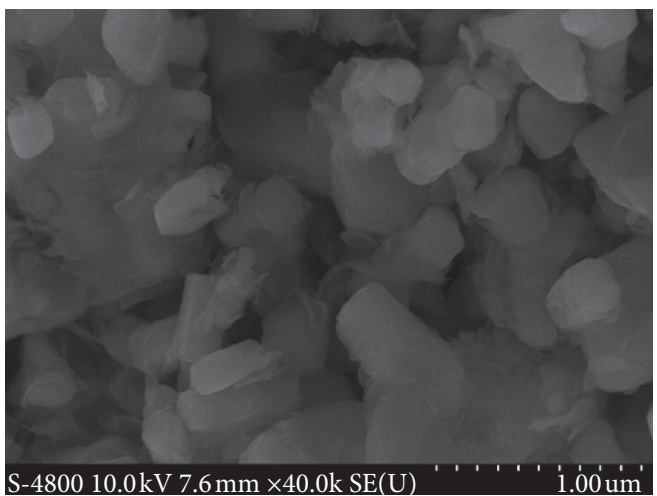

(b)

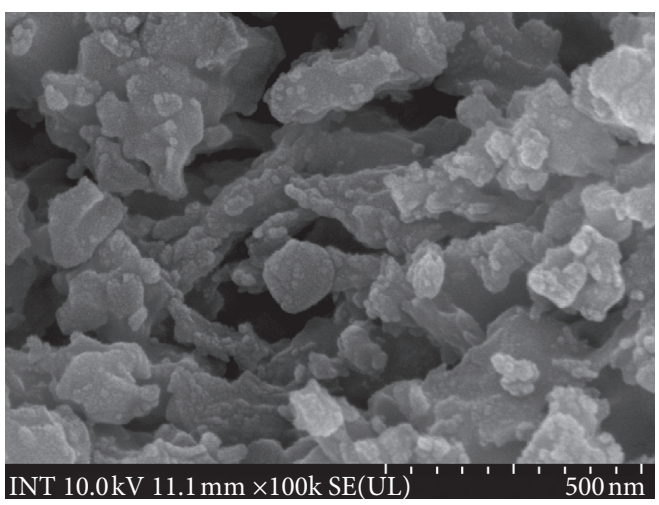

(c)

Figure 3: SEM images of (a) $\mathrm{Ni}_{-}-\mathrm{TiO}_{2}$; (b) Ni-ZnO; and (c) Ni-VPO.

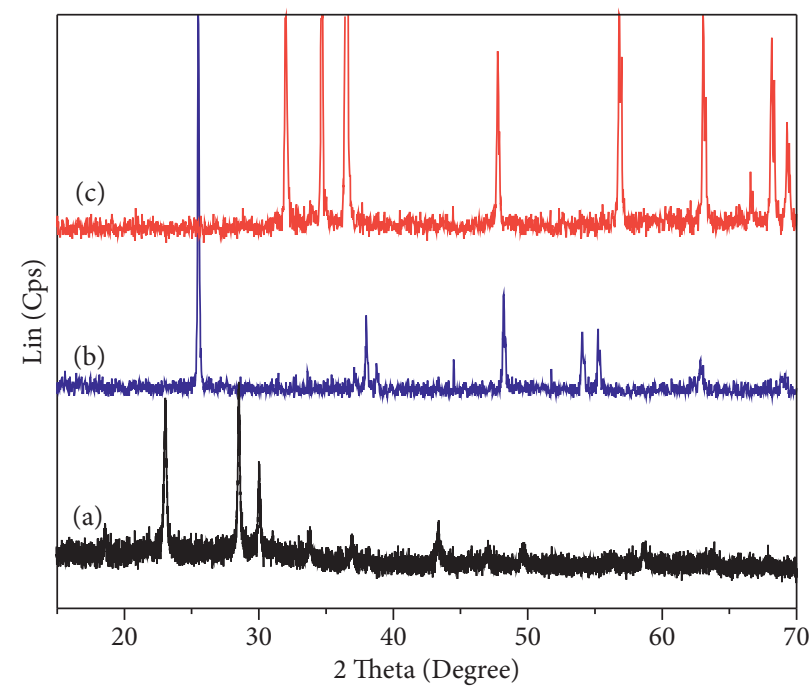

FIgURE 4: XRD patterns of Ni-X catalysts: (a) Ni-VPO; (b) $\mathrm{Ni}^{-\mathrm{TiO}_{2}}$; and (c) $\mathrm{Ni}-\mathrm{ZnO}$.

In order to evaluate the hydrodechlorination efficiency of the catalysts, $2.0 \mathrm{~mol} \%$ of $\mathrm{Ni}-\mathrm{X}$ catalysts was used to hydrodechlorinate the solution of 3-chlorophenol in the presence of sodium hydroxide. All the results are summarized in Figure 5, in which every $30 \mathrm{~min}$, the reaction mixture was centrifuged, the filtrate was directly connected to GC measurement, and the spectra of the chlorinated substrate before and after reaction were illustrated in Figure 6. The catalytic hydrodechlorination exhibited an excellent conversion of substrate in the presence of sodium hydroxide. In reality, Rong et al. carried out the reaction in strong base, and the reaction equilibrium has intention to move to the 


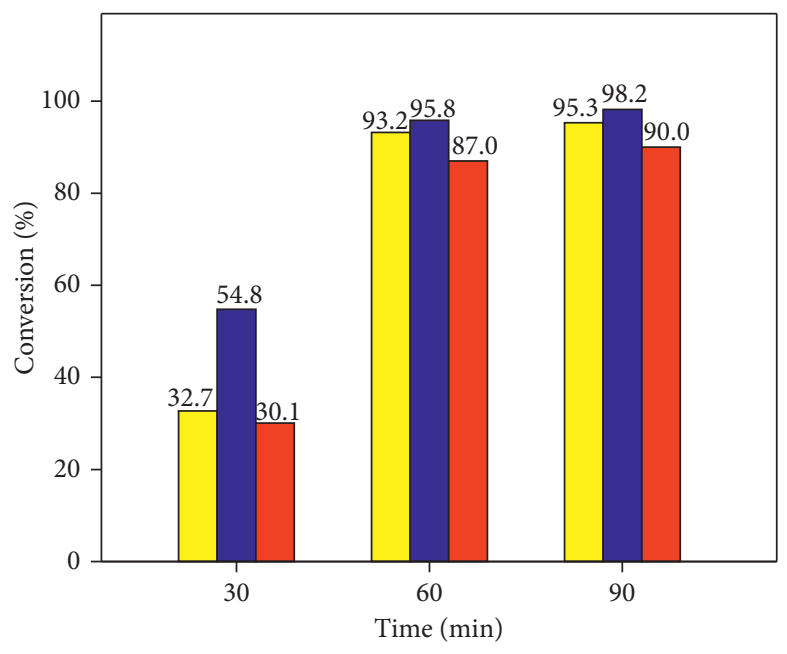

$\mathrm{Ni}-\mathrm{TiO} 2$

$\mathrm{Ni}-\mathrm{ZnO}$

$\mathrm{Ni}-\mathrm{VPO}$

Figure 5: Conversion of 3-chlorophenol over Ni-X catalysts vs. time reaction.

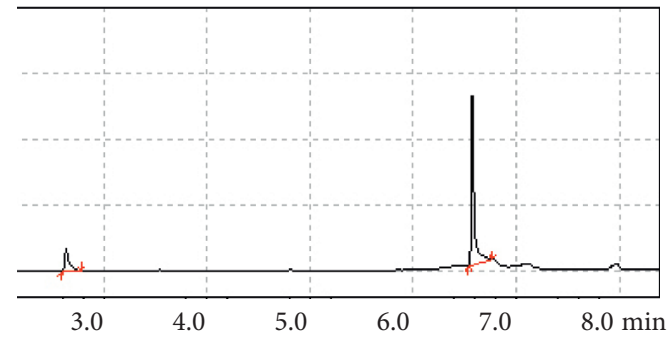

(a)

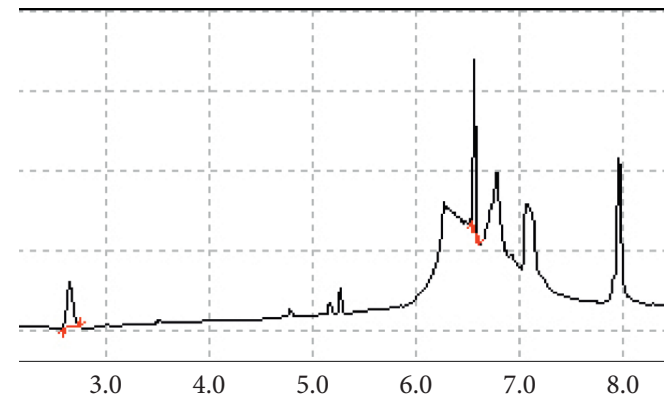

(c)

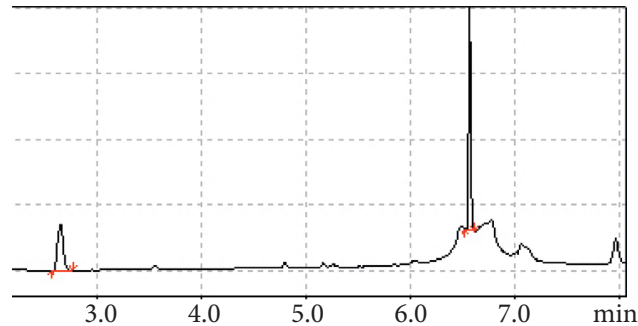

(b)

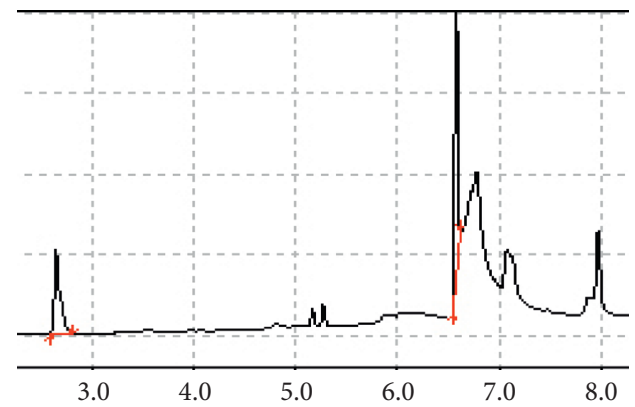

(d)

FIGURE 6: GC spectra of (a) starting materials (6.7 min) with internal standard (2.7 min); (b) with Ni-VPO; (c) Ni- $\mathrm{ZnO}$; and (d) with Ni-TiO 2 after 90 min reaction.

product in high rate. In contrast, the reaction rate is sluggish when the base is weak [20]. It could be one of the reasons why the reaction reached the end within $90 \mathrm{~min}$.

Another reason besides the high activity of $\mathrm{Ni}$ nanoparticles, parent supports also affect the conversion of hydrodechlorination of 3-chlorophenol. As illustrated in Table 1, the specific surface area of parent supports is quite higher than the supported one. This can be explained that most of Ni particles were impregnated inside the supports, and they could decrease the volume of the pores. Meanwhile,
TABLE 1: Specific surface area of catalysts.

\begin{tabular}{lc}
\hline $\mathrm{X} /$ Catalysts & $\mathrm{S}_{\mathrm{BET}}\left(\mathrm{m}^{2} \cdot \mathrm{g}^{-1}\right)$ \\
\hline $\mathrm{VPO} / \mathrm{Ni}-\mathrm{VPO}$ & $97 / 40$ \\
$\mathrm{TiO}_{2} / \mathrm{Ni}-\mathrm{TiO}_{2}$ & $47 / 20$ \\
$\mathrm{ZnO} / \mathrm{Ni}-\mathrm{ZnO}$ & $36 / 24$ \\
\hline
\end{tabular}

these particles are the activity centers of the catalyst which adsorbs both the hydrogen atoms and 3-chlorophenol on the surface. Therefore, the conversion of hydrodechlorination of 


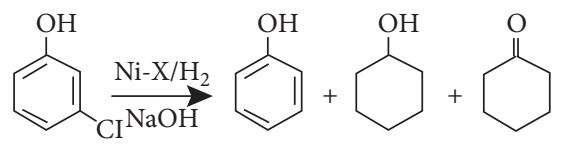

Scheme 1: The hydrodechorination pathways of 3-chlorophenol over Ni-X catalyst under liquid phase [9].

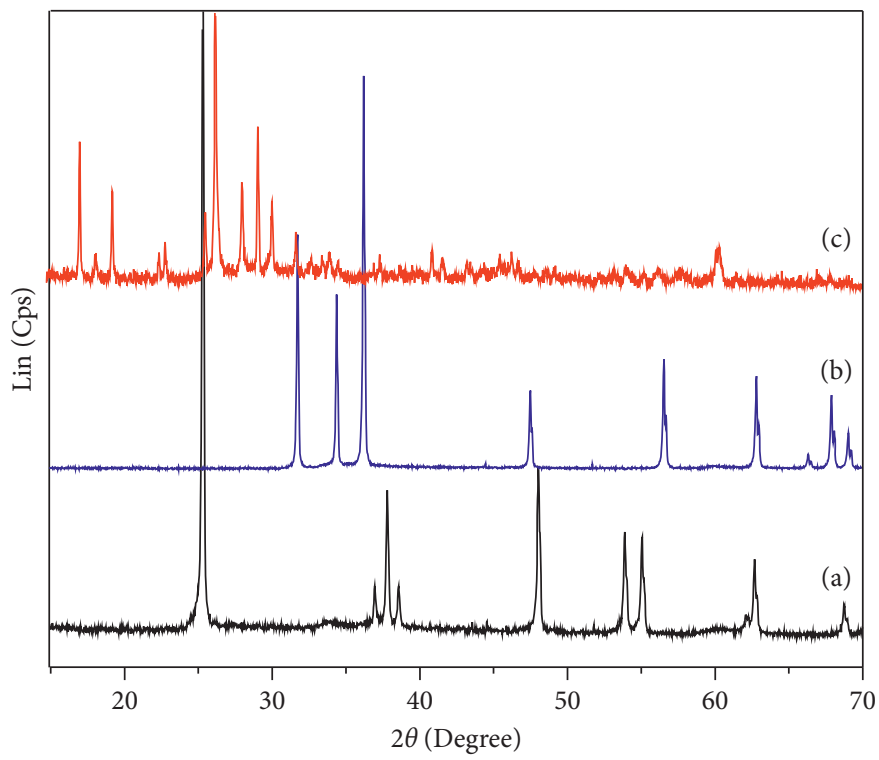

Figure 7: XRD patterns of recovered Ni-X catalysts after 3 runs: (a) $\mathrm{Ni}^{-\mathrm{TiO}_{2}}$; (b) $\mathrm{Ni}-\mathrm{ZnO}$; and (c) Ni-VPO.

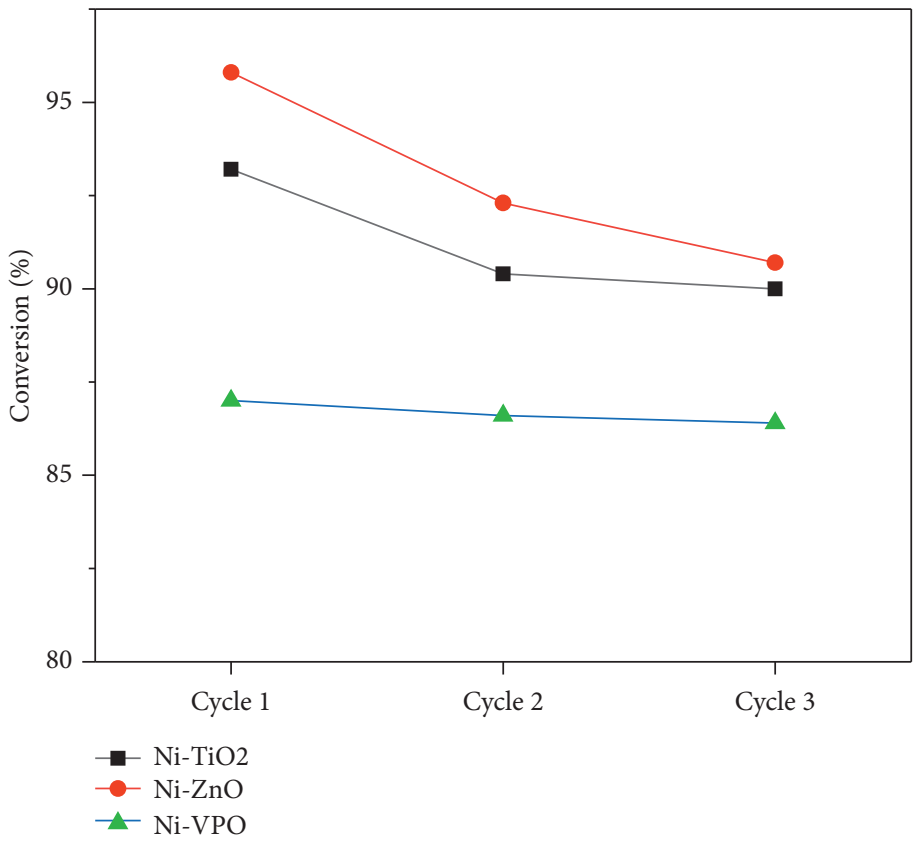

FIGURE 8: The conversion of 3-chlorophenol in hydrodechlorination with recovered Ni-X catalysts. Reaction condition: catalysts (2 mol\%); methanol as a solvent in the presence of $5 \%$ aqueous solution of $\mathrm{KOH}$ at RT within $1 \mathrm{~h}$.

3 -chlorophenol rised up via reaction time and reached to $98.2 \%$ within $90 \mathrm{~min}$ in the case of $\mathrm{Ni}-\mathrm{ZnO}$ as shown in Figure 5. No significant difference could be distinguished in the case of $\mathrm{Ni}-\mathrm{TiO}_{2}$, and the conversion was up to $95.3 \%$ within 90 min. Besides, Ni-VPO catalyst illustrated the high activity to the hydrodechlorination as well, even though it is 
quite lower than other cases, namely, $90 \%$ conversion within 90 min was observed. It could be explained in terms of the content of $\mathrm{Ni}$ particles in the sample. Literally, the nickel concentration was found to be only $2.47 \mathrm{wt} \%$ on VPO, whereas 11.71 and $13.11 \mathrm{wt} \%$ on $\mathrm{TiO}_{2}$ and $\mathrm{ZnO}$, respectively, in spite of the specific surface area of VPO is higher than the other ones (Table 1) [21]. These results indicated that the chlorine substrate was smoothly dechlorinated and converted into the dechlorination products as shown in Scheme 1.

The stability of Ni-X catalysts was evaluated by the hydrodechlorination of 3-chlorophenol, in which the procedure was repeated several times with the recovered catalysts. After each runs, the catalyst was recovered by centrifuging, washing, and drying at 60o $\underline{\mathrm{o}}$ under vacuum within $6 \mathrm{~h}$. Figure 7 showed the XRD patterns of recovered $\mathrm{Ni}$-X catalysts after three cycles, in which $\mathrm{Ni}^{0}$ nanoparticles appeared at $2 \theta$ angle of $44.55^{\circ}$ and $51.78^{\circ}$ as the same samples observed in Figure 4. It indicated that no significant change was obtained after three cycles hydrodechlorination of 3-chlorophenol, even though the intensity of peaks was lightly lower than the original samples, except Ni-VPO sample (Figure 7(c)) which could not give any signal of the $\mathrm{Ni}^{0}$ particle. It could be explained in terms of the missing of $\mathrm{Ni}^{0}$ nanoparticles after several runs. Indeed, the recovered catalysts determined the content of Ni particles by the AAS analysis, and it was found that $2.06,11.20$, and $12.54 \mathrm{wt} \%$ of $\mathrm{Ni}^{0}$ particles were distributed in $\mathrm{VPO}, \mathrm{TiO}_{2}$, and $\mathrm{ZnO}$ supports, respectively.

Besides, Figure 8 illustrated the conversion of 3-chlorophenol in the hydrodechlorination with recovered $\mathrm{Ni}-\mathrm{X}$ catalysts in the presence of 5\% aqueous solution of potassium hydroxide at RT within $1 \mathrm{~h}$. The conversion remains almost over $97 \%$ compared to the first run. Especially, in the case of Ni-VPO, the catalytic activity obtained no significant change, namely, 87.0, 86.6, and $86.4 \%$ conversion for the first run, second runs, and third runs, respectively. These indicated that good activity and stability of the $\mathrm{Ni}^{0}$ catalyst were observed.

\section{Conclusions}

In this report, the Ni-supported $\mathrm{X}\left(\mathrm{X}=\mathrm{VPO}, \mathrm{TiO}_{2}, \mathrm{ZnO}\right)$ was successfully synthesized by the reduction of nickel salt. All the physiochemical characterization of catalysts was presented in detail. In reality, TEM and XRD showed that nickel particles' size was around $15 \mathrm{~nm}$ and are incorporated as $\mathrm{Ni}^{0}$ inside X. Alternatively, the catalytic test indicated that almost supported catalysts exhibited high catalytic activity and stability, in particular, in the case of $\mathrm{Ni}-\mathrm{ZnO}$, the conversion of 3-chlorophenol reached $98.2 \%$ within $90 \mathrm{~min}$ in the presence of sodium hydroxide.

\section{Data Availability}

The data used to support the findings of this study are included within the article.

\section{Conflicts of Interest}

The authors declare that there are no conflicts of interest regarding the publication of this paper.

\section{Acknowledgments}

This research was funded by Vietnam National University Ho Chi Minh City (VNU-HCM) under grant number C2019-18-13.

\section{References}

[1] B. Jürgen, Chlorine and Caustic Soda Applications, Chlorine Production Plants 2018 Capacities, World Chlorine Council, Johannesburg, South Africa, 2018, https://www. chlorineindustryreview.com/manufacturing-applications/.

[2] N. Paidimarri, U. Virendra, and S. Vedantam, "Simultaneous recovery of hydrogen and chlorine from industrial waste dilute hydrochloric acid," International Journal of Chemical Engineering, vol. 2016, 2016.

[3] G. Chehade, N. Alrawahi, B. Yuzer, and I. Dincer, "A photoelectrochemical system for hydrogen and chlorine production from industrial waste acids," Science of the Total Environment, vol. 712, Article ID 136358, 2020.

[4] W. Li, D. Liu, D. Shen, L. Hu, J. Yao, and Y. Long, "Migration of inorganic chlorine during thermal treatment of mineralized waste," Waste Management, vol. 104, pp. 207-212, 2020.

[5] L. Qian, Y. Chen, D. Ouyang et al., "Field demonstration of enhanced removal of chlorinated solvents in groundwater using biochar-supported nanoscale zero-valent iron," Science of the Total Environment, vol. 698, pp. 134215-134226, 2020.

[6] J. Liu, X. Gong, S. Song, F. Zhang, and C. Lu, "Heat-activated persulfate oxidation of chlorinated solvents in sandy soil," Journal of Spectroscopy, vol. 2014, 2014.

[7] P. Luekittisup, V. Tanboonchauy, J. Chumee, S. Predapitakkun, R. W. Kiatkomol, and N. Grisdanurak, "Removal of chlorinated chemicals in H2Feedstock using modified activated carbon," Journal of Chemistry, vol. 2015, pp. 1-9, 2015.

[8] M. T. Amin, A. A. Alazba, and U. Manzoor, "A review of removal of pollutants from water/wastewater using different types of nanomaterials," Advances in Materials Science and Engineering, vol. 2014, pp. 1-24, 2014.

[9] C. Xia, Y. Liu, J. Xu, J. Yu, W. Qin, and X. Liang, "Catalytic hydrodechlorination reactivity of monochlorophenols in aqueous solutions over palladium/carbon catalyst," Catalysis Communications, vol. 10, no. 5, pp. 456-458, 2009.

[10] K. Wiltschka, L. Neumann, M. Werheid et al., "Hydrodechlorination of hexachlorobenzene in a miniaturized nano- $\operatorname{Pd}(0)$ reaction system combined with the simultaneous extraction of all dechlorination products," Applied Catalysis B: Environmental, vol. 275, pp. 119100-119109, 2020.

[11] Y. Peng, "Bimetallic composition-promoted electrocatalytic hydrodechlorination reaction on silver-palladium alloy nanoparticles," ACS Catalyst, vol. 49, no. 5AB, pp. 456-462, 2019.

[12] D. Comandella, S. Woszidlo, A. Georgi, F.-D. Kopinke, and K. Mackenzie, "Efforts for long-term protection of palladium hydrodechlorination catalysts," Applied Catalysis B: Environmental, vol. 186, pp. 204-211, 2016.

[13] G. Zhang, H. Xu, Y. Fan, Y. Wang, L. Zhang, and G. Lu, "Catalytic hydrodechlorination of trichlorobenzenes with $\mathrm{Pd}($ phen)Cl2as catalyst precursor," Journal of Nanomaterials, vol. 2015, pp. 1-8, 2015.

[14] Y. Xu, J. Ma, Y. Xu et al., "Nickel nanoparticles embedded in the framework of mesoporous TiO2: efficient and highly stable catalysts for hydrodechlorination of chlorobenzene," Applied Catalysis A: General, vol. 414, no. 414, pp. 350-357, 2012. 
[15] T. T. Co and P. A. V. Ho, "A highly efficient oxidation of styrene over vanadium phosphorus oxide catalysts using hydrogen peroxide," Vietnam Journal of Chemistry, vol. 49, no. $5 \mathrm{AB}$, pp. 456-462, 2011.

[16] P. Song, L. Liu, A.-J. Wang, X. Zhang, S.-Y. Zhou, and J.-J. Feng, "One-pot synthesis of platinum-palladium-cobalt alloyed nanoflowers with enhanced electrocatalytic activity for ethylene glycol oxidation," Electrochimica Acta, vol. 164, pp. 323-329, 2015.

[17] J. Mathiyarasu and K. L. N. Phani, "Carbon-supported palladium-cobalt-noble metal $(\mathrm{Au}, \mathrm{Ag}, \mathrm{Pt})$ nanocatalysts as methanol tolerant oxygen-reduction cathode materials in DMFCs," Journal of The Electrochemical Society, vol. 154, no. 11, pp. 1100-1105, 2007.

[18] P. Kim, J. B. Joo, W. Kim, J. Kim, I. K. Song, and J. Yi, "NaBH4-assisted ethylene glycol reduction for preparation of carbon-supported Pt catalyst for methanol electro-oxidation," Journal of Power Sources, vol. 160, no. 2, pp. 987-990, 2006.

[19] D. Li and S. Komarneni, "Microwave-assisted polyol process for synthesis of Ni nanoparticles," Journal of the American Ceramic Society, vol. 89, no. 5, pp. 1510-1517, 2006.

[20] H. Rong, S. Cai, Z. Niu, and Y. Li, "Composition-dependent catalytic activity of bimetallic nanocrystals: AgPd-catalyzed hydrodechlorination of 4-chlorophenol," ACS Catalysis, vol. 3, no. 7, pp. 1560-1563, 2013.

[21] H. Zhao, C. Zuo, D. Yang, C. Li, and S. Zhang, "Effects of support for vanadium phosphorus oxide catalysts on vaporphase aldol condensation of methyl acetate with formaldehyde," Industrial \& Engineering Chemistry Research, vol. 55, no. 50, pp. 12693-12702, 2016. 